\title{
Dr Edward Rigby of Norwich (1747-1821) and antepartum haemorrhage
}

\author{
Peter M Dunn
}

Edward Rigby was born on 27 December 1747 at Chowbent in Lancashire, the son of Sarah and John. He was educated at Joseph Priestly's Academy in Warrington before being apprenticed to David Martineau, a surgeon in Norwich. ${ }^{1} \mathrm{He}$ also attended Dr William Hunter's lectures in London before being admitted to the Corporation of Surgeons at the age of 22 . That year, 1769 , he began to practise in Norwich and just six years later in 1775 published his most important work: "An essay on uterine haemorrhage which precedes delivery of the full grown fetus". ${ }^{2}$ It went through several English editions and was also published in France, Germany, America, Russia, and Italy, bringing him distinction at the young age of 29.

In his essay, Rigby gave the first description of premature separation of the normally implanted placenta. He termed this "accidental" haemorrhage, in contradistinction to the "unavoidable" haemorrhage from placenta praevia (fig 1). The experience he reported of 44 cases was excellent and not surpassed for more than a century. Of his 30 cases of accidental haemorrhage, 25 were treated by rupture of the membranes and 28 mothers and 20 of the children survived. Of the 14 cases of placenta praevia, he lost only one mother and six babies. By the sixth edition in 1822, his series had swelled to 106 cases (64 cases of accidental haemorrhage and 42 cases of placenta praevia). The following extract is taken from his essay. ${ }^{2}$

\section{On antepartum haemorrhage}

"No circumstances that attends parturition, exposes women to so much danger, as profuse haemorrhages from the uterus, towards the latter end of pregnancy, and in the time of labour; the art of midwifery is likewise, in no instance, more at a loss in the use of means for the relief of the patient; an inquiry into the causes of them, and an attempt to improve the practice in such cases, cannot, therefore, be useless ... .

There is no particular part of the uterus, to

University of Bristol, Department of Child Health, Southmead Hospital, Southmead, Bristol BS10, UK PM Dunn

Correspondence to: Professor Dunn which nature seems constantly and uniformly to fix the placenta. It is nevertheless, for the most part, so situated, that if the woman be healthy, and no accident befall her, it does not separate till the full term of pregnancy, nor then before the entire expul-

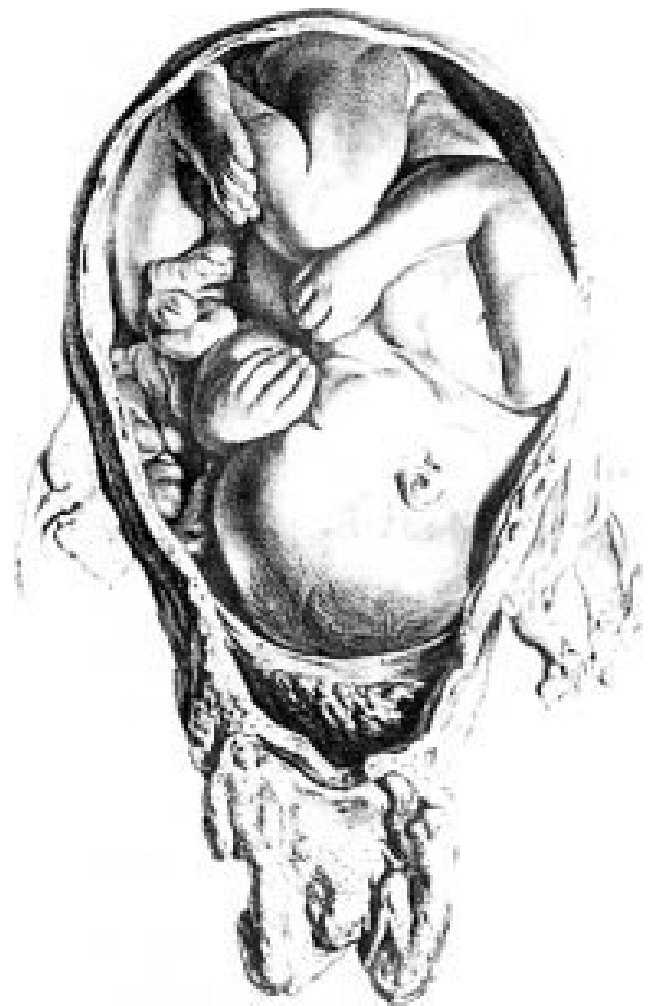

Figure 1 Engraving by $\mathcal{f}$ van Rymsdyk of a term fetus and placenta praevia. (Taken from Hunter. ${ }^{3}$ )

sion of the child, after which it becomes disengaged from the uterus, and is thrown off, making room for its entire contraction, which shutting up the mouths of the vessels, effectually prevents any considerable loss of blood; for which purpose, it is plain, it must be fixed to some part of the womb which does not dilate during labour, namely to the fundus or sides of it.

In this case, then, when a flooding comes on before the delivery of the child, it is obvious that the separation of the placenta must be owing to some accidental circumstance, to violence done to the uterus by blows, or falls, to some peculiar laxity of the uterine vessels from badness of habit, or fever, or so the influence of the passions of the mind suddenly excited, such as fear, anger, etc ...

But from the uncertainty, with which (as before observed) nature fixes the placenta to the uterus, it may happen to be so situated, 
that when the full term of pregnancy is arrived, and labour begins, a flood necessarily accompanies it, and without the intervention of any of the above accidental circumstances; that is, when it is fixed to the part of the womb which always dilates as labour advances, namely, the collum and os uteri, in which case, it is very certain that the placenta cannot, as before described, remain secure till the expulsion of the child, but must of necessity, be separated from it, in proportion as the uterus opens, and, by that means, an haemorrhage must unavoidably be produced.

That floodings, which arise from these two different causes, which I will distinguish by the names of accidental and unavoidable, though they may appear exactly similar in their first symptoms, should terminate very differently, if left to nature, assisted only by the palliating means before mentioned, cannot seem strange; nor can it be a doubt that of these two kinds of floodings, only one of them, namely, that which is produced by an accidental separation of the placenta can be relieved by the use of these palliatives; and that the other, in which the placenta is fixed to the os uteri, and the flooding is therefore unavoidable, cannot possibly be suppressed by any other method whatever, than the timely removal of the contents of the womb."

Rigby added: " . . . it has been suggested that I have borrowed my theory from Levret (André Levret, 1703-80). After remarking the gross folly I should have been guilty of in quoting Levret, had I furtively adopted his opinions, it will I trust be sufficient for me unequivocally to declare that my original ideas on the subject were derived solely from my own personal observation and experience; and that having previously neither read nor heard of the placenta being ever fixed to the os uteri, the knowledge of such a circumstance, derived as before observed, came to me and impressed me as a discovery."

Edward Rigby wrote further essays on a number of medical subjects including the pro- duction of animal heat and its application in disease (1785), on the use of red Peruvian bark in the care of intermittents (1783), and on the vaccination of Norwich paupers (1813). But his interests were even wider. He had bought a farm at Framingham five miles from Norwich, and wrote on the agriculture of his own country (including an essay on the improved cultivation of the mangel wurzel) as well as on that of France and Italy after a visit to the Continent in 1789. In 1786 he was foremost in establishing the Norfolk Benevolent Society for the relief of the widows and orphans of medical men. He also took a great interest in the care of the poor and the management of the city's workhouse. In 1783 he became a member of the Corporation of the Guardians of Norwich, in 1802 an alderman, in 1803 sheriff, and in 1805 was elected mayor of the city. It is also of considerable interest that although he had been in general practice since 1769 and had an international reputation, Rigby did not take a degree in medicine until 1814 at the age of 67 .

Edward married twice. His first wife, Darah Dybal, whom he married in 1769 , bore him two daughters, while his second, the daughter of William Polgrave of Yarmouth, whom he married in 1803, gave him no less than 12 children, including twins in 1804 and quadruplets (three girls and one boy) in 1817, when he had reached the age of 70 . One of the twins, also named Edward (1804-60) became a very distinguished London obstetrician. Edward Rigby, senior, died on 27 October 1821 at the age of 74 and was buried at Framingham.

1 Graham H. William Hunter and Dr Slop. Eternal eve. London: W Heinemann, 1950:329-331.

2 Rigby E. An essay on the uterine haemorrhage, which precedes the delivery of the full grown fetus. London: J Johnson, 1775. 6 th ed (1822). Printed by Burks and Kinnebrook, Norwich for Hunter, London.

3 Hunter W. The anatomy of the grand uterus. Birmingham: Baskerville, 1774 